\title{
A life-cycle analysis of ending mandatory retirement
}

\author{
Katerina Koka \\ Department of Economics, Brock University, Canada \\ kkoka@brocku.ca \\ Stephen Kosempel \\ Department of Economics and Finance, University of Guelph, Canada \\ kosempel@uoguelph.ca
}

\section{Department of Economics and Finance University of Guelph Discussion Paper 2013-12}

Accepted Manuscript@ Economic Modelling

(C) 2013, Elsevier. Licensed under the Creative Commons Attribution-Non Commercial-

No Derivatives 4.0 International http://creativecommons.org/licenses/by-nc-nd/4.0/

The final publication of this article is available at www.elsevier.com

DOI: http://dx.doi.org/10.1016/j.econmod.2013.11.042 


\title{
A life-cycle analysis of ending mandatory retirement*
}

\author{
Katerina $\mathrm{Koka}^{\dagger}$ \\ Department of Economics \\ Brock University \\ Stephen Kosempel ${ }^{\ddagger}$ \\ Department of Economics and Finance \\ University of Guelph
}

November 14, 2013

\begin{abstract}
In this paper a life-cycle model is constructed to study the macroeconomic effects and welfare implications associated with eliminating mandatory retirement. Our short run analysis reveals that changes in welfare during the transition depend on the dynamic nature of the wage rate adjustment process. We distinguish between transitions in which the wage rate clears the labour market and transitions with a sticky wage and youth unemployment. We also examine political feasibility by measuring the popular support that this type of policy might have under the two labour market scenarios. Finally, we identify the effects that the policy has on welfare in the long run. JEL classification:
\end{abstract} E24, E61

*We would like to thank participants at the 43rd Annual Conference of the Canadian Economic Association, the 39th Annual Conference of the Eastern Economic Association, the Rimini Conference in Economics and Finance, and seminar participants at the University of Guelph, for their valuable comments and discussions.

${ }^{\dagger}$ Corresponding Author, Department of Economics, Brock University, St. Catharines, Ontario, L2S 3A1. Email: kkoka@brocku.ca, Phone: 1(905)688-5550 ext. 4270, 1(416)897-7003

${ }_{\ddagger}^{\ddagger}$ Department of Economics and Finance, University of Guelph, Guelph, Ontario, N1G 2W1. Email: kosempel@uoguelph.ca 


\section{Introduction}

In this paper we study the macroeconomic effects and welfare implications associated with eliminating mandatory retirement. The analysis is performed using a large scale life-cycle model of the type developed by Auerbach and Kotlikoff (1987). The model features heterogeneous individuals with a lifetime labour $\backslash$ leisure choice and endogenous retirement decisions. The model is calibrated with data from Canada and policy experiments are performed by removing mandatory termination of work. The reason for applying the model to study the Canadian experience is that in recent years several of Canada's provinces have abolished the policy of mandatory retirement. ${ }^{1}$ Our analysis deals explicitly with policy short and long term macroeconomic effects and potential welfare gains and losses. In addition, we are also able to capture age specific outcomes that may arise in the course of the policy implementation process.

This paper is related in both methodology and consideration of a change in the statutory retirement age as a policy option to a large body of literature that has studied reforms to social security systems. These reforms have been proposed in the hope of alleviating pressures that arise from aging populations. Auerbach and Kotlikoff (1984) were the first to employ a large life-cycle model to study social security reforms in the U.S. economy. However, many studies followed, simulating the model by using parameters and demographic patterns specific to different countries. For example, extending retirement as part of pension reforms has been proposed and studied in life-cycle models by Hviding and Merette (1998) for a number of OECD countries; De Nardi, Imrohoroglu and Sargent (1999), and Conesa and Garriga (2003) for the U.S.; Hirte (2002) for Germany; Lassila and Valkonen (2002) for Lithuania;

\footnotetext{
${ }^{1}$ The remaining of Canadian provinces have joined Alberta, Manitoba, Quebec and Prince Edward Island in banning the policy of mandatory retirement. These include Ontario in 2006, Newfoundland and Labrador and Saskatchewan in 2007, British Columbia in 2008 and Nova Scotia in 2009.
} 
Henin and Weitzenblum (2003) for France; Beetsma, Bettendorf and Broer (2003) for the Netherlands; Keuschnigg and Keuschnigg (2004) for Austria; and Hongxin and Merette (2005) for China. ${ }^{2}$

Unemployment effects are examined in only two of these studies. Hirte (2002) models under-employment that persists over the life-cycle due to a constant difference between the cost of labour and its marginal product, resulting to part of the individual time being employed and part of it being unemployed at each stage of the life-cycle. Keuschnigg and Keuschnigg (2004) look at pension reforms in a model that captures long run search unemployment.

We depart from the literature mentioned above in several respects. First, we model transitional unemployment for new entrants in the labour market, which in the model economy correspond to young generations. In this way we address one popular concern related to the policy of ending mandatory retirement which is the possibility of creating youth unemployment. Unemployment at early stages of the life-cycle is important for welfare outcomes as it may prevent individuals to build up necessary assets for retirement and induce them to work longer for the rest of their lifetime. Thus we examine transitional periods that follow two types of wage adjustment scenarios: a flexible wage which clears the labour market and a sticky wage which follows a slower adjustment and creates unemployment. We are able to compare welfare gains and losses in these two types of transitional structures, and in the long run equilibrium.

Second, we investigate age specific welfare outcomes at the start of each transitional path with clearing and non-clearing transitional labour markets. Any welfare changes of generations alive at this period will affect public support for the new pol-

\footnotetext{
${ }^{2}$ The initial work of Auerbach and Kotlikoff (1987) was followed by numerous studies aimed at analyzing unsustainable social security systems. In this literature review, we only consider studies that include retirement reforms in the suggested policy remedies.
} 
icy. Thus we examine whether banning involuntary retirement is a feasible political equilibrium that is supported by a majority vote.

Third, we examine the effects of banning mandatory retirement in Canada. In provinces which previously allowed mandatory retirement the normal age of retirement was typically at the age of 65 . Although six percent of workers continue to work full-time after the normal age of retirement, the current average retirement age in Canada is 62. Thus, it would appear that the policy might have small or no effect on economic outcomes and individual welfare. However, data from labour force surveys in the period 1997 to 2006 suggest that a trend to retire early, particularly prevalent in 1990s, may be reversing (see Burbidge and Cuff (2007)). It is likely that this trend may continue to reverse due several reasons: Firstly, an aging population due to low fertility rates and combined with the baby boom generation will increase the number of old workers in the workforce (Martel, Caron-Malenfant, Vzina and Blanger (2007)); secondly, improvements in health and longevity allow for the possibility to work longer (Hogan and Lise (2003)); and thirdly, younger people now spend more time studying than in the past, and thus might increase years spent at work by choosing to work later in life (Beaujot (2004)).

To preview our main results, we find that when comparing long run equilibrium outcomes with and without mandatory retirement, new entrants in the labour market would actually prefer to be born in an economy with mandatory retirement. Welfare outcomes are also lower for individuals born during the transition to a voluntary retirement economy, and the reduction in welfare varies with the type of the wage rate adjustment process. In particular, individuals who enter the economy in a transition where wage rates are flexible to adjust experience a lesser reduction in welfare than individuals born in the long run with voluntary retirement or a transition where wage rates are slow to adjust. Despite the fact that welfare is lower for all agents 
born after the policy change, for a majority of the current population welfare can be improved by removing the mandatory retirement rule. As a result, our measures of political feasibility concerning voters alive at the time of the policy announcement to end mandatory retirement indicate that the policy is supported by a majority vote.

The rest of the paper is organized as follows: The model is outlined in section 2 and calibrated in section 3. Policy experiments are performed and discussed in section 4. Concluding remarks are provided in section 5.

\section{The benchmark economy}

We model a variant of the Auerbach and Kotlikoff (1987) life-cycle economy. At each discrete point in time overlapping generations of individuals differ with respect to their age, labour productivity endowments, probability of surviving into the next period, employment status and asset holdings. A new cohort enters the economy in every model period. Individuals live for a finite number of years and typically work for a large faction of their lifetime. They are also faced with a period consumption/leisure choice in order to maximize their lifetime utility. The model has a pay-as-you-go public pension plan with flexible drawing dates which collects contributions from working individuals and redistributes funds to the current retired population or workers eligible to receive pension benefits.

\subsection{Demographics}

We assume that the demographic structure of the population is stationary. ${ }^{3}$ The population grows at a constant rate $n$. The length of individual life lasts for a

\footnotetext{
${ }^{3}$ The demographic structure in Canada is non-stationary, and the population's average agent is aging. However, in order to isolate the effects of ending mandatory retirement, these demographic changes must be addressed in a separate paper.
} 
maximum of $J$ model periods. At each age $j$, for $j=1, . . J-1$, the conditional probability of surviving from age $j$ to age $j+1$ is given by $\psi_{j} \in(0,1)$. The probability of becoming $s$-years old is then $\prod_{j=1}^{s}\left\{\psi_{j}\right\}$. A new generation enters and leaves the economy with certainty; consequently $\psi_{0}=1$ and $\psi_{J}=0$. The fraction of each cohort in the total population is constant and given by $\mu_{j+1}=(1+n)^{-1} \mu_{j} \psi_{j}$ with $\sum_{j=1}^{J} \mu_{j}=1$

\subsection{Individual problem}

Each individual derives utility from consumption, $c_{j}$, and leisure $l_{j}$. The objective of a new entrant in the economy is to maximize her expected discounted lifetime utility:

$$
E_{0} \sum_{j=1}^{J} \beta^{j-1}\left[\Pi_{s=1}^{j} \psi_{s}\right] U\left(c_{j}, l_{j}\right)
$$

where $\beta$ is the subjective discount factor.

The life of an economic agent is characterized by a working period and a retirement period. Individuals are endowed with one unit of time per period which they can choose to divide between working activities, $h_{j}$, and leisure, $l_{j}=1-h_{j}$. Average labour productivity varies with age. In particular, we assume that one unit of time, if devoted to work, can be converted to $z_{j}$ efficiency units of labour. The benchmark economy is characterized by a mandatory retirement age which is denoted by $j r$. Individuals retire if they reach this age or if they do not choose to supply any positive amount of labour time. ${ }^{4}$

New generations enter the economy with zero assets. Income of the working young is generated from earnings from labour services and interest payments on

\footnotetext{
${ }^{4}$ Thus, in the benchmark economy the working life of an individual may vary but it continues for a maximum of $j r-1$ periods.
} 
accumulated assets. Retired older agents consume pension benefits, their private savings and interest returns. In periods of low income, consumption and leisure may be financed by borrowing. By the end of their lifespan, individuals pay any accumulated debt or deplete all of the remaining assets. Let $q_{j}$ and $k_{j}$, respectively, indicate disposable non-capital income and individual private savings. The price of consumption goods is normalized to one. Also, relative factor prices are denoted by $r$ and $w$ for capital and labour, respectively. The budget constraint facing an individual is given by:

$$
k_{j+1, t+1}=\left(1+r_{t}\right) k_{j, t}+q_{j, t}-c_{j, t}
$$

Non-capital income, $q_{j}$, includes disposable labour income and $\backslash$ or pension benefits, $b$. A contribution tax to the pension plan, $\tau$, is applied to labour income for most of the working life. If individuals are eligible and elect to receive benefit payments, the contribution tax is removed. Pension benefits are intended to replace a fraction of an individual's labour income during retirement, however, the retirement age $(j r)$ and the age that benefits are received $(j b)$ may differ. The model places no restriction on the number of hours that pension recipients will decide to supply, should they continue to work. In this way the model mimics the flexible structures of Canada's pension plans. Finally, all individuals receive or pay lump-sum government transfers or taxes, $t r$. We assume that any accidental bequests left by individuals are equally redistributed through government transfers to surviving members of the population. Thus, an individual's non-capital income is given by:

$$
q_{j, t}=\left\{\begin{array}{ccc}
(1-\tau) w_{j, t} z_{j} h_{j, t}+t r & \text { for } & j=1, . ., j b-1 \\
w_{j, t} z_{j} h_{j, t}+b+t r & \text { for } & j=j b, . ., j r-1 \\
b+t r & \text { for } & j=j r, . ., J
\end{array}\right.
$$


In Canada, workers have some control over the size of their annual pension benefit level. In particular, the replacement rate of labour income that is used to determine the annual benefit level from the Canada Pension Plan (CPP) depends on the date that an individual elects to start receiving benefits. Pension benefits may be received at any time between the age of 60 and the age of 70 . An individual that elects to delay receiving benefits is rewarded with a higher replacement rate, and therefore a higher benefit level. However, the date benefits are first received may differ from the retirement date, since the CPP allows contributors to collect benefits while maintaining employment. Since the age that an individual elects to receive pension benefits does not depend on the employment decision, the model can be solved in two stages: In stage $1, j b$ and $b$ are set to maximize the net present value of a pension, taking as given the formula outlined in the CPP. We will revisit this stage when the model is calibrated. In stage 2 , agents optimize, treating $j b$ and $b$ as exogenous parameters.

\subsection{Production}

Aggregate output, $Y_{t}$, is produced via a constant returns to scale Cobb-Douglas technology. Firms are owned by households, who employ capital, $K_{t}$, and efficient labour input, $H_{t}$, to produce the final output:

$$
Y_{t}=A_{t} f\left(K_{t}, H_{t}\right)
$$

where $A_{t}$ indicates the level of total factor productivity. Aggregate capital depreciates at the rate $\delta$. Firms maximize profits in each period. Relative factor prices that solve the firm's problem are given by: $w_{t}=A_{t} f_{h}\left(K_{t}, H_{t}\right)$ and $r_{t}=A_{t} f_{k}\left(K_{t}, H_{t}\right)-\delta$. Each individual receives the average wage rate in the economy times a factor that depends on her productivity level. 


\subsection{The pension plan}

The public pension plan collects payroll taxes from workers and accidental bequest, $B_{t}$. These funds are distributed to current retired or older workers who are eligible for benefits in each period. The government is required to maintain a balanced budget; surpluses or shortages are removed via a lump-sum transfer/tax, tr. The government's budget constraint is given by:

$$
\tau \sum_{j=1}^{j b-1} \mu_{j} w_{j, t} z_{j} h_{j, t}+B_{t}=b \sum_{j=j b}^{J} \mu_{j}+t r
$$

where any assets received from non-survivors are calculated as:

$$
B_{t}=\sum_{j=1}^{J}\left(1-\psi_{j}\right) \mu_{j} k_{j, t}
$$

\subsection{Equilibrium}

The recursive structure of the representative agent's problem is used to compute the competitive equilibrium of the model economy. For a given set of policy parameters and an initial distribution of capital assets $\left\{k_{j, 0}\right\}_{j=1}^{J}$, the model's competitive equilibrium consists of a set of age dependent but time invariant productivity measures of agents types $\left\{z_{j}\right\}_{j=1}^{J}$; a set of relative prices for capital and labour $\left\{r_{t}, w_{t}\right\}$; a set of allocations for the representative firm $\left\{K_{t}, H_{t}, Y_{t}\right\}$ and a set of policy rules

for the representative agent of each cohort $c_{j, t}\left\{k_{j, t}, K_{t}, H_{t}\right\}, h_{j, t}\left\{k_{j, t}, K_{t}, H_{t}\right\}$ and $k_{j+1, t+1}\left\{k_{j, t}, K_{t}, H_{t}\right\}$, such that: (i) individual and aggregate behaviour are consistent, $K_{t}=\sum_{j=1}^{J} \mu_{j} k_{j, t}$ and $H_{t}=\sum_{j=1}^{J} \mu_{j} z_{j} h_{j, t}$; (ii) given relative prices the allocation of the representative firm solves the firm's optimization problem; (iii) given relative prices and government pension policy, the individual policy rules of the representative agent solve her optimization problem; (iv) commodity markets clear, 
$\sum_{j=1}^{J} \mu_{j}\left(c_{j, t}+k_{j+1, t+1}\right)=Y_{t}+B_{t}+(1-\delta) \sum_{j=1}^{J} \mu_{j} k_{j, t} ;$ and $(\mathrm{v})$ the government budget constraint given by equation (5) is balanced.

Before the equilibrium values can be determined, parameter values must be set and the dynamic problem must be solved. A description of the algorithm that was used to solve the dynamic problem can be found in Heer and Maussner (2005).

\section{Calibration}

The benchmark economy is calibrated to match the long run average of aggregate outcomes in the Canadian economy. If the calibrated model is able to capture specific targets, then policy experiments of ending mandatory retirement can be performed to analyze its macroeconomic implications. In this section we discuss parameters and specific functional forms that are used in the model.

\subsection{Demographics}

The model period corresponds to one year in real time. New entrants in the economy participate in the labour market and thus are assumed to be 21 years old. Individuals may live for a maximum of 80 years, therefore $J=60$. Survival probabilities are taken from the Life Tables (2002) of Statistics Canada and are computed for each age group as averages of female and male probabilities. We assume that these survival

probabilities are invariant over time. In the benchmark economy the mandatory retirement age is $65(j r=45)$, corresponding to a common retirement age in most Canadian provinces which previously allowed mandatory retirement. We calibrate the population growth rate, $n$, to $1.14 \%$, an average for Canada over the last thirty years. 


\subsection{Technology and Endowments}

The Cobb-Douglas functional form that is used to produce output is: $Y_{t}=A_{t} K_{t}^{\alpha} H_{t}^{1-\alpha}$. The share of labour income to total income, $(1-\alpha)$, is calculated to be 0.645 and matches the value in Canada. Following Gomme et al. (2004), the annual depreciation rate of fixed and non-fixed capital assets, $\delta$, takes a value of 0.0504 . The value of the technology parameter, $A$, is set to 1 . We assume that age profiles of labour productivity are also time invariant. Values for productivity weights, $\left\{z_{j}\right\}_{j=1}^{J}$, are taken from Hansen (1993).

\subsection{Preferences}

The period utility function takes the form: $U(c, l)=\frac{\left[c l^{\gamma}\right]^{1-\eta}}{1-\eta}$. Here $\eta$ is the coefficient of relative risk aversion and $\gamma$ is a parameter that reflects disutility from working. We set the coefficient of relative risk aversion equal to 2, a value commonly used in the macroeconomic literature (Mehra and Prescott (1985)). The discount factor, $\beta$, and the parameter representing disutility from work, $\gamma$, are set jointly to match as closely as possible the average capital-output ratio and investment-output ratio in the data. Their values are 0.99 and 1.38, respectively. The selected parameters also produce an average labour supply during the individual's working life equal to estimates computed from Canadian employment data. In particular, from annual data on hours worked using labour force survey estimates from 1976 to 2006, we calculate the average time spent in working activities to be 0.2893 . In the model this value is 0.2886 . 


\subsection{Pension Parameters}

The pension system in the model incorporates features of the CPP. The contribution tax rate, $\tau$, is set to 9.9 percent and is equal to the sum of contribution rates of both employers and employees. When selecting the optimal date to collect pension benefits, $j b$, agents face a trade-off between the duration of benefits and the benefit level $b$. We link $j b$ to $b$ via the formula specified in the CPP, which provides flexibility with respect to both the replacement rate, $\theta$, and the age that agents can begin collecting benefits. For example, for people who choose to collect pension benefits at age 65 , the CPP replaces 25 percent of their average annual earnings during their contributory period. However, for people who elect to receive their pension benefits between age 60 and 64 , the replacement rate will be reduced by 0.5 percent for each month that they are under age 65 . The maximum reduction is 30 percent at age 60 . On the other hand, for people who elect to delay receiving their retirement benefits until they are between age 66 and 70, the replacement rate will be increased by 0.5 percent for each month over 65 to a maximum of 30 percent at age 70 . After the age of 70 , there is no further change in the replacement rate, and therefore there is no incentive to delay receiving benefits any longer. There is one additional benefit to receiving the pension early - once pension benefits begin, an agent no longer pays the contribution tax.

We perform a value grid search to find the optimal age for agents to collect benefits, and the corresponding replacement rate. The CPP imposes restrictions to discourage eligible workers to obtain their pensions while working before the age of 65. These restrictions are complementary to low replacement rates and include requirements for a period of unemployment or low income below a preset maximum amount. Nevertheless, we assume that these restrictions are not preventive and allow for individuals in the model to be able to receive benefits as soon as they are eligible 
and if they choose to do so. The grid search analysis revealed that agents, given our specified demographic parameters, will choose to receive their pension benefits starting at the age of 60 , and this is true regardless of whether they continue to be employed. In other words, at age 60 the net present value of their pension is

maximized. Therefore, in the model, the benefit level, $b=\frac{\theta \sum_{j=1}^{j b} w z_{j} h_{j}}{j b}$, is set to produce a replacement rate of 17.5 percent.

When transitional dynamics are analyzed, we fix the rate at which the parameter $b$ adjusts to its long run value. In particular, we assume a slow linear adjustment. This procedure will allow the replacement rate to deviate slightly from the 17.5 percent value that is used in the long run equilibria. We have done this for two reasons. First, this procedure reduces the computation burden of calculations. Second, the CPP has other provisions (too numerous to model) that will allow the replacement rate to deviate temporarily from its long run value. For example, it allows workers to remove a certain number of periods of low income from their calculation of the average income. Essentially, our procedure for setting $b$ during the transition will mean that workers will not have labour income included in their benefit calculation during periods of unemployment.

\section{Results}

\subsection{Policy experiments}

We assume that, initially, the economy is in its long run equilibrium. Then, the government announces a policy that removes the practice of mandatory retirement, which starts being effective in the next period. Retirees of the previous policy arrangement are allowed to renegotiate a contract and re-enter the labour market. We assume two types of transitional periods: in the first transition the wage rate re- 
sponds quickly to changes in the labour supply, while in the second, the wage rate follows a slower adjustment. But before proceeding to an analysis of the transitional dynamics, we discuss outcomes of the benchmark economy and compare the long run equilibrium associated with the two mandatory retirement rules.

\subsection{Outcomes in the benchmark economy}

The long run in the benchmark economy is characterized by constant aggregate variables and factor prices. As a result, the distribution of specific outcomes over the life-cycle of a typical individual will also correspond to the distribution of period outcomes across age groups. ${ }^{5}$ As mentioned before, a new generation enters the labour market with zero asset holdings and allocates a fraction of their time endowment to work. In early stages agents are endowed with low productivity profiles and consumption is financed from borrowed funds and income from work. Later in life, to smooth consumption and leisure profiles over the life-cycle and provide for old age, individuals devote part of their period income to private savings.

Age dependent distributions for capital assets, employment, consumption and productivity weights are depicted in figures 1,2, 3 and 4, respectively. Individual series for savings start off slightly negative due to initial individual borrowing. Then they rise with age, peak before retirement and fall until fully depleted at the end of the lifetime. The age employment structure follows a similar pattern except labour supply is the highest when individuals are relatively younger. Employment falls as individuals accumulate more savings and with declining productivity measures. Consumption follows a relatively smooth profile except at ages 60 and 65. At age 60, the consumption level jumps up and at 65 it jumps down. The intuition for this is as follows: Optimal behaviour for a utility maximizing agent requires that the marginal

\footnotetext{
${ }^{5}$ This is no longer the case in the transitional phase.
} 
utility of consumption maintain a reasonably flat profile. However, given our calibration, both leisure and consumption affect the marginal utility of consumption negatively, so any changes in leisure must be offset by changes in consumption. At age 60, agents begin collecting pension benefits and the contribution tax is removed. The removal of the tax encourages agents to work more and have less leisure. Since leisure declines, consumption must increase. In comparison, at age 65 agents must retire, leisure rises a lot and therefore consumption falls.

\subsection{Long run effects}

In this section we compare the long run of a mandatory retirement economy with a voluntary retirement economy by aggregate and age specific outcomes. Aggregate variables and factor prices for both steady states are presented in Table 1 along with relative responses of outcomes from the benchmark economy. We observe that, removing mandatory retirement results in a lower capital stock accumulation and a higher level of employment. The new steady state also leads to a higher level of output and consumption. All variations of aggregate variables from the benchmark economy, with the exception of employment, are within the two percent range. On the other hand, employment increases by 2.18 percent. Since factors of production are paid their marginal products, both the average wage rate and interest rate are determined by relative changes in the level of capital and employment. The voluntary retirement economy is associated with a lower average wage rate and a higher interest rate. Furthermore, the level of benefits earned by benefit recipients is also lower following smaller individual contributions to the CPP over the working life.

Age specific outcomes of moving from mandatory to voluntary retirement are reported in Table 2, panel A. The results indicate that removing mandatory retirement is associated with a reschedule of the individual age labour supply over the 
life-cycle. In the new policy regime, employment is lower for middle age groups, but extended over a longer period of time. The labour supply of younger individuals is higher, because they are faced with less favourable factor prices. In addition to a lower average wage rate, young individuals are confronted with a higher interest rate which increases their cost of borrowing.

Also, the removal of mandatory retirement is associated with a positive response of the labour supply of older workers above the age of 65 . Given our productivity weights and chosen value of parameter $\gamma$, work for people aged over 65 amounts on average to 6.3 percent of a unit of time. ${ }^{6}$ Several reasons may explain this increase. Firstly, a ban on mandatory retirement allows agents to achieve a smoother lifetime age-leisure profile, which is desirable for a utility maximizing agent with a positive but diminishing marginal utility of leisure. Secondly, working longer may yield higher work income over the life-cycle which in turn allows for higher consumption. Thirdly, the contribution to the pension plan stops when workers start receiving their pension benefits. The elimination of the contribution tax raises the effective wage paid to older workers.

In the voluntary retirement economy, individuals also borrow less and thus save more when relatively young due to a higher cost of borrowing. Relatively middle aged agents, specifically from age 45 to 69 , accumulate lower capital assets, since working longer reduces incentives to save prior to retirement. Consumption in the voluntary retirement economy is lower for the first part of the life-cycle, from age 21 to 49 , but higher for the remainder of the individual's life-cycle. Essentially, when retirement is voluntary, agents compensate for less leisure time when old by consuming more. ${ }^{7}$

\footnotetext{
${ }^{6}$ For older workers $(65+)$ most of the additional time they work occurs before age 70 .

${ }^{7} \mathrm{~A}$ sensitivity analysis is also performed to examine the robustness of our results by varying the structural parameters of the model. We find that outcomes due to the removal of mandatory retirement are robust to most variations in parameter values.
} 


\subsection{Transitional effects}

We consider two types of transitional dynamics: in the first one, the wage rate responds quickly to changes in the labour supply and in the second one, it follows a slower adjustment process. The analysis of transitional dynamics is based on comparisons between cohorts born in the old steady state, the new steady state and at the beginning of each transition. The importance of looking at agents born at the time of the policy announcement stems from the fact that they will experience the entire adjustment period of aggregate variables and factor prices.

We assume that the slower wage transition arises from frictions in the labour market. A sticky wage creates unemployment among new entrants in the labour force which in our model are young generations. In particular, we set the wage rate equal to the marginal product of an average worker in the initial steady state which in turn also determines the level of unemployment. The wedge between the clearing market wage and the actual wage rate paid to workers continues for three periods and then it is allowed to adjust to its new steady state level. The number of periods that the wage remains fixed was chosen arbitrarily. Nonetheless, we believe this type of experiment is useful in that it will reveal how sensitive our results are to the presence of youth unemployment.

In figures 5 and 6 we depict the transitional dynamics for aggregate capital and employment, respectively, for each adjustment type of the wage rate. In addition, figures 7 and 8 show the time paths of the average wage rate and interest rate from one steady state to another. ${ }^{8}$ Individual outcomes during transition for each wage adjustment process are provided in table 2, panel B.

We first notice that for all aggregate variables and prices, the transition with a clearing labour market converges faster to the economy's new long run equilib-

\footnotetext{
${ }^{8}$ Each figure depicts the first 80 periods of the estimated transitional path.
} 
rium. In the flexible wage transition, the level of employment is higher compared to the economy with mandatory retirement. This is in part due to the older workers extending their retirement date, and in part due to young individuals working longer hours. We also observe that aggregate capital gradually declines to its new equilibrium level. Since factor prices are determined by production input's marginal products, as employment rises and the aggregate capital falls, the average wage rate falls and the interest rate rises to their respective new levels.

The evolution of capital is determined by a number of factors. As working income declines, young cohorts aged 21-30 will have an incentive to borrow more funds and support the beginning stages of life, however as the interest rate increases, the cost of borrowing also rises. Panel $\mathrm{B}$ of table 2 shows that in the transition with flexible wages savings increase for this age group. The middle age group, 31-65, accumulates lower savings, because the possibility of work later in life combined with lower earnings from work (from both less hours of work and a lower wage rate) dominates the incentive to save more due to a higher interest rate. For agents over age 65, savings are higher due to positive work income even though their pension income is lower than in the mandatory retirement economy.

The slow wage transition follows similar patterns, but with more pronounced effects at the beginning of the transition. Employment initially declines due to the presence of youth unemployment for the first few periods. As Figure 7 shows, once previously unemployed workers enter the labour market, the wage rate drops by more than the observed drop of the wage rate in the flexible wage transition. As a result, the response of aggregate savings is larger in magnitude compared to the transition with market clearing.

The same is the case for the market interest rate. Moreover, the data in panel B of table 2 reveals that the disadvantage of being unemployed at early stages in the 
slow wage transition reduces both consumption and savings of transitional cohorts for the remainder of their life-cycle. Individuals in this type of transition borrow funds for a longer period of time and once employed, work more hours throughout their life-cycle.

\subsection{Welfare effects}

We follow Imrohoroglu et al. (1995) and measure welfare effect by computing the compensating variation as the fixed percentage of consumption $\Delta$ at each age that is required to make individuals living in transitional economies or the long run economy with voluntary retirement indifferent to living in the benchmark economy. Therefore:

$$
V\left\{\left(c_{j}, l_{j}\right) \mid m r\right\}=E_{0} \sum_{j=1}^{J} \beta^{j-1}\left[\Pi_{s=1}^{j} \psi_{s}\right] U\left\{\left((1+\Delta) c_{j}, l_{j}\right) \mid v r\right\}
$$

where $V\left\{\left(c_{j}, l_{j}\right) \mid m r\right\}$ and $V\left\{\left(c_{j}, l_{j}\right) \mid v r\right\}$ denote the expected discounted lifetime utilities for individuals born in the equilibrium with mandatory and voluntary retirement policies, respectively. The percentage consumption compensation is given by:

$$
\Delta=\left(\frac{V\left\{\left(c_{j}, l_{j}\right) \mid m r\right\}}{\left.V\left\{\left(c_{j}, l_{j}\right) \mid v r\right)\right\}}\right)^{\frac{1}{1-\eta}}-1
$$

Table 3 depicts these welfare outcomes. Our results show that agents born in an economy with mandatory retirement are better off than agents born in the first transitional period or the long run with voluntary retirement. However, agents entering the labour market at the beginning of the transitional period with flexible wages require a smaller consumption compensation than agents entering the transition with sticky wages or the economy with voluntary retirement. In particular, in the transition with clearing labour markets the compensation variation as percent of consumption in each period of life is 0.026 . Recall that throughout their life-cycle 
transitional agents will experience the entire adjustment of aggregate variables and prices. As a result, agents born in the transition with flexible wages benefit from the ability to achieve at older age higher consumption levels. At the same time, at early stages of the economic life, declining wage rates combined with increasing interest rates negatively affect their welfare outcomes. Since both factor prices remain close to values in the mandatory retirement regime when agents enter the flexible wage transition, the negative impact of the price adjustment on these individuals is relatively smaller.

Next, agents born in a scenario where wages do not clear the labour market in transition require 2.51 percent increase in per period consumption in order to be indifferent with outcomes in the benchmark steady state. These agents borrow higher amounts of funds to sustain a relatively smooth consumption profile. Their lower welfare is attributed to a lower age consumption profile and a higher age employment profile over the life-cycle with the exception of unemployment periods.

Finally, in each period of life, individuals in the voluntary retirement economy require a 0.24 percent increase in consumption to be as well off as if they were born in the mandatory retirement economy. ${ }^{9}$ In other words, when comparing long run equilibria, the constrained economy (the mandatory retirement economy) has a better outcome than the unconstrained economy. The reason for this is that mandatory retirement solves a coordination problem that exists in the unconstrained economy. The coordination problem is explained as follows: When agents are forced to retire early, aggregate employment is lower, because the fraction of the retired population is higher; and the capital stock is higher, because people must save more to support them during a longer retirement period. These differences in labour and capital both affect the aggregate wage positively in the constrained economy. Therefore,

\footnotetext{
${ }^{9}$ The results are similar if a lump sum tax is used to fund the pension plan in the model rather than a proportional tax.
} 
the benefit of mandatory retirement is that it pushes wages up during the periods in which agents are eligible to work. However, if given a choice a given worker would always choose to work beyond the age of 65 , and this is true regardless of the decisions of the other agents. ${ }^{10}$ Extending the working life beyond 65 is a dominate strategy, but produces a Nash equilibrium in the long run which is inefficient.

Since there are both costs and benefits associated with a policy of forced retirement, there must be an optimal age to set mandatory retirement. The model can be used to predict this value by iterating on the mandatory retirement date $j r$. Our iterations revealed that having mandatory retirement at age 63 is an optimal policy if the objective is to maximize welfare in the long run. Why then have Canadian provinces banned the policy of mandatory retirement? A possible explanation is identified in the next section.

\subsection{Voting}

While continuing to distinguish between the two types of transitional dynamics, we estimate the political feasibility of reform by measuring the popular support of ending mandatory retirement. The welfare gains and losses of the current population at the time of the policy announcement will determine the outcome of the voting behaviour. Therefore, voting members are defined as individuals born in the mandatory retirement economy who are alive when the new policy is announced.

At the start of transition, individuals re-optimize their consumption and leisure profiles taking into account changes in the retirement policy and prices. We measure the expected discounted lifetime utility of every voting member and create a utility index $I$ which measures their decision. Denoting the date of the policy change by $t_{0}$

\footnotetext{
${ }^{10}$ The benefit of extending the retirement age beyond 65 is that an agent can obtain a smoother labour-leisure profile, and can generate more labour income over the entire life-cycle.
} 
and the type a transition by $T$, the index is calculated as:

$$
I=\frac{E_{0}\left\{\sum_{j=1}^{t_{0}} \beta^{j-1}\left(\prod_{s=1}^{j} \psi_{s}\right) U\left(c_{j}, l_{j} / m r\right)+\sum_{j=t_{0}+1}^{J} \beta^{j-1}\left(\prod_{s=1}^{j} \psi_{s}\right) U\left(c_{j, t}, l_{j, t} / T\right)\right\}}{E_{0}\left\{\sum_{j=1}^{J} \beta^{j-1}\left(\prod_{s=1}^{j} \psi_{s}\right) U\left(c_{j}, l_{j} / m r\right)\right\}}
$$

If $I>1$ then the voting member is worse off because of the new policy and vice versa. ${ }^{11}$ Figure 9 and Figure 10 depict voting outcomes for the two types of transition dynamics for all individuals of different ages at the start of each transition. We find that all of the members in the flexible wage rate transition and the majority of members in the sticky wage rate transition are in favour of the new retirement rule. The members who strongly prefer voluntary retirement are middle aged individuals. They are able to not only maintain a more desirable labour-leisure profile but also earn higher capital income on previously accumulated capital assets. Younger and older members are also better off, however, their benefits are not as high as middle age groups. Particularly, older workers receive smaller benefits than in the mandatory retirement economy although they also enjoy higher returns on their asset holdings. The outcomes for young workers are similar to those of agents entering the economy at the beginning of each type of transition period which were described in section 4.4 .

\section{Conclusion}

In this paper we have looked at aggregate and age specific outcomes, as well as welfare considerations of removing mandatory retirement. Unlike similar literature on pension reforms which extend the date of retirement, we analyze this policy

\footnotetext{
${ }^{11}$ Note that utility values are negative.
} 
independently, focusing our attention on transitional and welfare outcomes. Perhaps our most interesting finding is that although the policy is preferred by a majority of voters alive at the time of the policy implementation, it eventually leads to a decline in individual welfare. The model also reveals that welfare differences and responses of aggregate variables and prices during the transitional phase will depend on the degree of frictions in the labour market. We observe following a short period of wage stickiness more pronounced aggregate changes and slower convergence to a new equilibrium. Agents born in the transition with a slower wage adjustment also experience a higher welfare reduction than agents born in the transition with flexible wages and the equilibrium with voluntary retirement.

\section{References}

Auerbach, A.J., and L.J. Kotlikoff (1984) 'Simulating Alternative Social Security Responses to the Demographic Transition.' NBER Working Paper

- (1987) Dynamic Fiscal Policy (Cambridge,MA: Cambridge University Press)

Beaujot, R. (2004) 'Delayed Life Transitions: Trends and Implications.' Ottawa: Vanier Institute of the Family

Beetsma, R., L. Bettendorf, and P. Broer (2003) 'The Budgeting and Economic Consequences of Aging in the Netherlands.' Economic Modelling 20, 987-1013

Burbidge, J., and K. Cuff (2007) 'Mandatory Retirement and Incentives in Private Pension Plans.' Retirement Policy Issues in Canada

Conesa, J.C., and C. Garriga (2003) 'Status Quo Problem in Social Security Reforms.' Macroeconomic Dynamics 7, 691-710

De Nardi, M., S. Imrohoroglu, and T.J. Sargent (1999) 'Projected U.S. Demographics and Social Security.' Review of Economic Dynamics 2, 575-615 Gomme, P., R. Rogerson, P. Rupert, and R. Wright (2004) 'The Business Cycle and the Life Cycle.' NBER Macro Annual pp. 415-461

Hansen, G.D. (1993) 'The Cyclical and the Secular Behaviour of the Labour Input: Comparing Efficiency Units and Hours Worked.' Journal of Applied Econometrics 8(1), 71-80

Heer, B., and A. Maussner (2005) Dynamic General Equilibrium Modeling Computational Methods and Applications: Ch.8 (Springer)

Henin, P.Y., and Th. Weitzenblum (2003) 'Welfare Effects of Alternative Pension Reforms : Assessing the Transition Costs for French Socio-Occupational Groups.' Society for Computational Economics: Computing in Economics and Finance 2003 
Hirte, G. (2002) 'Welfare and Macroeconomic Effects of the German Pension Acts of 1992 and 1999: A Dynamic CGE Study.' German Economic Review $3(1), 81-106$

Hogan, S., and J. Lise (2003) 'Life Expectancy, Health Expectancy and the Life Cycle.' Horizons 6, 2-9

Hongxin, L., and M. Merette (2005) 'Population Aging and Pension System Reform in China: A Computable OLG Model Analysis.' Journal of Chinese Economic and Business Studies 3(3), 263-277

Hviding, K., and M. Merette (1998) 'Macroeconomic Effects of Pension Reforms in the Context of Aging Populations: OLG Simulations for Seven OECD Countries.' OECD Working Paper

Imrohoroglu, A., S. Imrohoroglu, and D.H. Joines (1995) 'A Life Cycle Analysis of Social Security.' Economic Theory 6, 83-114

Keuschnigg, C., and M. Keuschnigg (2004) 'Aging, Labor Markets, and Pension Reform in Austria.' FinanzArchiv: Public Finance Analysis 60(3), 359-392

Lassila, J., and T. Valkonen (2002) 'Retirement Age Policies and Demographic Uncertainty in Lithuania: A Dynamic CGE Analysis.' The Research Institute of the Finish Economy-mimeo

Martel, L., C. Caron-Malenfant, S. Vzina, and A. Blanger (2007) 'Labour Force Projections for Canada, 2006-2031.' Canadian Economic Observer

Mehra, R., and E.C. Prescott (1985) 'The Equity Premium.' Journal of Monetary Economics 15, 145-161 
Table 1: Long run effects of removing mandatory retirement

\begin{tabular}{lccc}
\hline & $\begin{array}{c}\text { Benchmark } \\
\text { Economy }\end{array}$ & $\begin{array}{c}\text { Voluntary } \\
\text { Ret. Economy }\end{array}$ & $\begin{array}{c}\% \Delta \text { from } \\
\text { Bench. Econ. }\end{array}$ \\
\hline Aggregate Outcomes & & & \\
Capital & 2.1953 & 2.1705 & -1.1297 \\
Investment & 0.1106 & 0.1094 & -1.0850 \\
Employment & 0.2886 & 0.2949 & 2.1830 \\
Output & 0.5931 & 0.5992 & 1.0285 \\
Consumption & 0.4844 & 0.4917 & 1.5070 \\
Prices & & & -1.1166 \\
Average wage rate & 1.3255 & 1.3107 & 4.3956 \\
Interest rate & 0.0455 & 0.0475 & -2.1436 \\
Pension and transfers & & & -2.1789 \\
Pension income & 0.0872 & 0.0853 & -0.7979 \\
Government transfer & 0.0376 & 0.0373 & \\
Ratios & & 3.6227 & \\
Capital/output ratio & 3.7016 & 0.1826 & \\
Investment/output ratio & 0.1866 & & \\
\hline
\end{tabular}


Table 2: Average individual outcomes for separate age groups

\begin{tabular}{|c|c|c|c|c|}
\hline \multicolumn{5}{|c|}{ Age Groups } \\
\hline & $21-30$ & $31-65$ & $65+$ & Total \\
\hline \multicolumn{5}{|c|}{ Panel A: Long run individual outcomes } \\
\hline \multicolumn{5}{|c|}{ Mandatory retirement } \\
\hline Assets & 0.0920 & 2.9416 & 2.6604 & 2.4354 \\
\hline Consumption & 0.3426 & 0.5259 & 0.5424 & 0.4995 \\
\hline Employment & 0.4199 & 0.3855 & 0.0000 & 0.2949 \\
\hline \multicolumn{5}{|c|}{ Voluntary retirement } \\
\hline Assets & 0.1066 & 2.8846 & 2.6684 & 2.4059 \\
\hline Consumption & 0.3380 & 0.5256 & 0.5864 & 0.5096 \\
\hline Employment & 0.4214 & 0.3789 & 0.0625 & 0.3069 \\
\hline
\end{tabular}

Panel B: Transitional individual outcomes

Flexible wage transition*

$\begin{array}{lllll}\text { Assets } & 0.1103 & 2.8930 & 2.6681 & 2.4113 \\ \text { Consumption } & 0.3390 & 0.5261 & 0.5874 & 0.5102 \\ \text { Employment } & 0.4217 & 0.3782 & 0.0618 & 0.3064\end{array}$

Sticky wage transition*

$\begin{array}{lllll}\text { Assets } & -0.3556 & 2.4264 & 2.5160 & 2.0248 \\ \text { Consumption } & 0.3324 & 0.5135 & 0.5705 & 0.4975 \\ \text { Employment } & 0.3593 & 0.3920 & 0.0720 & 0.3065\end{array}$

*Agent born in the first period of transition

Table 3: Welfare outcomes

\begin{tabular}{lccc}
\hline & Voluntary ret. & Flex. transition & Slow transition \\
\hline $\begin{array}{l}\text { Percent consumption } \\
\text { compensation }\end{array}$ & 0.2474 & 0.0260 & 2.5135 \\
\hline
\end{tabular}



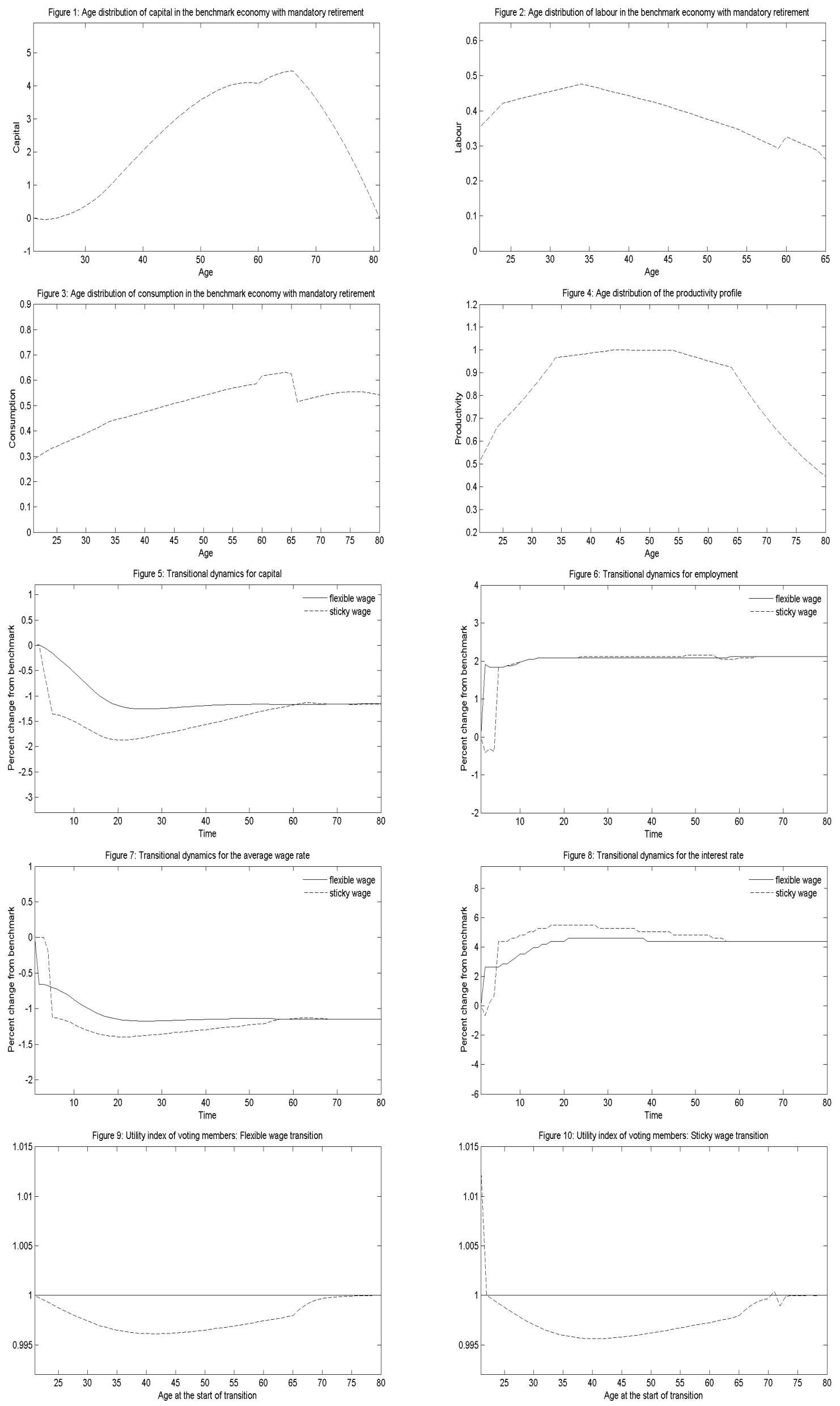